\title{
ORIGINAL
}

ARTICLES

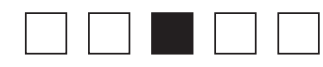

\section{A Longitudinal Study of Burnout and Well-being in Family Medicine Resident Physicians}

Mari Ricker, MD; Victoria Maizes, MD; Audrey J. Brooks, PhD; Coya Lindberg, MD; Paula Cook, BA; Patricia Lebensohn, MD

\begin{abstract}
BACKGROUND AND OBJECTIVES: The Accreditation Council for Graduate Medical Education (ACGME) core competencies for residency learning and work environment standards acknowledge high levels of burnout and depression in resident physicians and the critical importance of physician well-being to patient care and effective education. The objective of this study was to follow family medicine resident physicians' well-being throughout residency.
\end{abstract}

METHODS: Family medicine resident physicians from 12 programs completed validated assessments (burnout, depression, perceived stress, satisfaction with life, positive and negative affect, emotional intelligence, mindfulness, gratitude) at residency start, second year start, and graduation. Resident physicians were from the 2011, 2012, and 2013 graduating classes ( $N=158)$.

RESULTS: Two indicators of burnout (emotional exhaustion, depersonalization) increased between the start of residency and the start of the second year, remaining elevated at graduation. Emotional intelligence was lower at graduation than at the start of residency. In contrast, other measures of well-being (stress, life satisfaction, affect) improved during the second and third years. Depression, mindfulness, and gratitude remained stable. Increased levels of burnout risk at graduation were negatively associated with emotional intelligence, mindfulness, and gratitude.

CONCLUSIONS: While the stressful impact of residency is transitory for some measures of well-being, that is not the case for burnout or emotional intelligence. Burnout levels peak after the first year of residency and remain high through graduation. Targeted interventions to identify and address burnout in residency need to be evaluated in future studies.

(Fam Med. 2020;52(10):716-23.)

doi: 10.22454/FamMed.2020.179585

$\mathbf{R}$ esidency training is a challenging endeavor; between long work hours, sleep deprivation, limited time for self-care, unhealthy eating patterns, reduced exercise, and reduced time to spend with family and friends, residency is a personally taxing experience. The Accreditation Council for Graduate Medical Education (ACGME) core competencies for residency learning and work environment standards acknowledge high rates of burnout and depression in resident physicians and the critical importance of physician well-being to both patient care and effective education. ${ }^{1}$ The ACGME requirements include mandatory training for resident physicians and faculty members on ways to identify burnout, depression, and substance abuse, as well as provision of 24-hour access to mental health services. Programs are also required to promote greater professional identity formation through supportive measures such as "protecting time with patients, minimizing nonphysician obligations, administrative support, promoting progressive autonomy and flexibility, and enhancing professional relationships." Although vague, the requirements state that programs create "policies and programs that encourage optimal residency and faculty member well-being" and provide "opportunities for rest and personal well-being."

The ACGME requirements are one step toward addressing the serious prevalence of depression, burnout, and increased suicidality seen in medical trainees and physicians. Burnout negatively influences physician well-being, ${ }^{2,3}$ increases suicidal ideation,, 45 and worsens quality of care. ${ }^{6,7}$ Addressing the causes and implementing successful interventions at the trainee level is imperative. $^{8}$

From the Andrew Weil Center for Integrative Medicine, University of Arizona, Tucson, AZ (Drs Ricker, Maizes, Brooks, and Lebensohn, and Ms Cook); and the Cascades East Family Medicine Residency, Oregon Health and Science University, Klamath Falls, OR (Dr Lindberg). 
Burnout, Well-being, and

Protective Factors

The term "burnout" emerged as job burnout, and it has been used as a construct related to work specifically. ${ }^{9}$ Burnout is usually viewed as part of well-being and has been used to describe the feeling of emotional exhaustion, depersonalization or cynicism, and reduced personal accomplishment associated with chronic work stress. ${ }^{10}$ Rates of burnout amongst resident physicians range from $24 \%$ to $75 \%$ depending on specialty. ${ }^{11-14} \mathrm{~A}$ recent study found a burnout prevalence rate of $37 \%$ in postgraduate year (PGY) 2 family medicine resident physicians. ${ }^{13}$ Physician distress is not a new problem, but we have not made much improvement in nearly a decade. Survey results over time demonstrated improvements in satisfaction and burnout from 2011 to 2014, but then a recurrence of less satisfaction and high burnout in $2017 .{ }^{15} \mathrm{~A}$ systematic review found resident physicians reporting less work fulfillment than attending physicians. ${ }^{16}$

A survey of medical house staff found high levels of depressive symptoms in $34.8 \%$ of first-year resident physicians on ward rotations in $1985 .{ }^{17}$ In 2010 , Sen and colleagues reported depression increased from $3.9 \%$ at the onset of residency training to an average of $25.7 \%$ over the course of their internship year. ${ }^{18} \mathrm{~A}$ meta-analysis of over 50 studies concluded that around $29 \%$ of resident physicians experienced symptoms of depression, regardless of their year in residency. ${ }^{19}$ Depressed resident physicians are at higher risk of burnout, and once burnout emerges it tends to persist. ${ }^{20}$ Depression and burnout have both been associated with increased medical error rates. ${ }^{7,21}$

In general, well-being refers to a broad range of perceptions of individuals' current situation and state. ${ }^{22,23}$ In a 2016 systematic review of resident physician well-being, factors associated with well-being were positive relationships with colleagues, improved confidence in work, increasing perception of mastery, sense of control, positive feedback, learning opportunities, autonomy, goal achievement, sleep, and time away from work. ${ }^{16}$

From a training perspective, it is important to understand what the protective factors are for resident physicians' well-being during residency. Studies of surgery resident physicians found emotional intelligence, agreeableness and emotional stability personality traits, and positive job experiences protective against burnout. ${ }^{12}$ Emotional intelligence first defined by Salovey and Mayer refers to "the ability to monitor one's own and others' feelings and emotions, to discriminate among them and to use this information to guide one's thinking and actions."24

Greater mindfulness was associated with less burnout, stress, depression, anxiety, and suicidal ideation in surgical resident physicians. ${ }^{5}$ Gratitude, as part of positive emotion practices, has been identified as one of the potential protective factors in training physicians in combatting burnout. $^{25}$

Despite widespread awareness of the prevalence and seriousness of burnout and depression amongst physicians and trainees, and a variety of attempts to improve the situation, it is a continuing and increasing problem. ${ }^{13,26}$ Several studies on well-being interventions for resident physicians have demonstrated the potential to address burnout and depression, though most of these studies had small sample sizes or low participant response rate. In a review of burnout interventions in medical trainees, positive evidence for mindfulness training, specific breathing techniques, and group sessions for self-development reducing burnout were found. ${ }^{27}$

In this paper, we present results from a longitudinal study of the trajectory of multiple dimensions of burnout, well-being, and protective factors throughout residency. No studies to date have examined multiple indicators of well-being over the course of the 3 years of family medicine residency training across multiple residency programs. We assessed indicators of burnout, wellbeing (perceived stress, depression, affect, and satisfaction with life), and potential protective factors (emotional intelligence, mindfulness, and gratitude) in three cohorts of family medicine resident physicians from 12 residencies nationally. Eight of these residencies were recruited to implement and evaluate a novel curriculum called Integrative Medicine in Residency (IMR). The goal of the IMR curriculum is to provide education in integrative medicine at the residency level. IMR brings an evidence-based, 200-hour, interactive, online curriculum into an existing residency program. ${ }^{28,29}$ Four residencies served as a control group to evaluate several medical knowledge and skills outcomes associated with the teaching of integrative medicine. The aim of the present study is to examine the resident physicians' trajectory of multiple measures of burnout, well-being, and protective factors across 3 years of family medicine training in 12 residencies and to examine the relationship of burnout to the protective factors.

\section{Methods \\ Sample}

Two hundred fifty-one resident physicians at 12 family medicine residency programs with graduation dates of 2011 through 2013 were included. Eight of these family medicine residencies were recruited to pilot the online interactive IMR curriculum, while four family medicine residency programs were recruited to serve as a control group of resident physicians without formal education in integrative medicine. We sent an invitation to participate in the IMR pilot study to all family medicine residency faculty interested in teaching IM who could commit participation of all resident physicians in the program. Pilot sites were chosen to represent the heterogeneity seen in family medicine residency programs, eg, community and academic settings, and urban, suburban, and rural locations. IMR residencies 
were University of Arizona, Tucson, AZ; Beth Israel Medical Center, New York, NY; Carolinas Medical Center, Charlotte, NC; Hennepin County Medical Center, Minneapolis, MN; Maine-Dartmouth, Augusta, ME; Maine Medical Center, Portland, ME; University of Connecticut, Hartford, CT; and University of Texas Medical Branch, Galveston, TX. Half of the sites were university-based, while the other half were community-based programs. The number of resident physicians at the sites ranged between 21 and $33 .^{30}$

We obtained external funding for the second year of the project to recruit control sites. Three of the four control sites were community-based programs, with the number of resident physicians ranging between 24 and $36 .{ }^{30}$ Participating control residencies were Montefiore Medical Center, Bronx, NY; Moses Cone Memorial Hospital, Greensboro, NC; Providence Hospital, Anchorage, AK; and University of Minnesota, Minneapolis, MN. For the current longitudinal analyses, we included only resident physicians with assessments at the start of residency and graduation ( $\mathrm{n}=158 / 251 ; 63 \%)$. Resident physicians from IMR programs were from the 2011, 2012, and 2013 classes $(n=127)$, while resident physicians in the control programs were only from the 2012 and 2013 classes $(\mathrm{n}=31)$. The sample was primarily female $(63 \%)$, Caucasian (60\%), married/cohabitating (56\%), with average age of 30 years (range 24-53 years).

Analyses on demographic and baseline questionnaire data comparing resident physicians who completed both assessments $(\mathrm{n}=158)$ to those who did not ( $n=93)$ found assessment completers to be younger, however, age data was only available for $78.5 \%$ of the sample. In addition, negative affect was higher at baseline in resident physicians with both assessments completed. No other demographic or well-being differences were observed between assessment completers and noncompleters.

\section{Measures}

We selected well-being measures based on relevance and prior use with health care professionals. We used 10 validated instruments to measure burnout, multidimensional positive and negative aspects of well-being, and protective factors (Table 1).

\section{Data Collection and Analysis}

Resident physicians completed the assessments online using an individualized link to an internet-based survey website (SurveyMonkey). Prior to accessing the initial assessment, resident physicians completed an online informed consent. Resident physicians completed the assessments at the beginning of residency (PGY1), start of second year (PGY2), and prior to graduation. Approval for the study was granted by The University of Arizona Institutional Board (IRB) and the IRBs of participating institutions granted the study approval.

\section{Statistical Analyses}

Prior to combining the two groups for the longitudinal analyses, analyses were conducted to ensure comparability between groups. We conducted $\chi^{2}$ analyses and t tests to compare the IMR group with control group on baseline demographic and all wellbeing measures. To accommodate the difference in sample size between the groups and determine if the groups differed over time, we conducted a series of linear mixed-effect models ${ }^{44}$ using SAS Proc Mixed (SAS version 9.3) to examine the main effects of group (IMR vs control) and time (PGY1, PGY2, and graduation), and the interaction of group by time. In each of the models, we treated the independent variables as class variables, with person as the random effect. We reran the analyses, dropping nonsignificant effects. Due to significant baseline differences between groups on emotional exhaustion and depersonalization (see results below), these models also controlled for the baseline score. We examined pair-wise comparisons of means in the models with statistically significant effects. Significant effects for group main effect or group by time interactions would indicate differences between the IMR and control groups. Significant effects for time would indicate a change between groups between time points (PGY1, PGY2, and graduation) or change in the trajectory of a measure during residency. To explore the impact of burnout, we conducted a one-way analysis of variance with burnout risk level groups (Table 1) at graduation as the independent variable predicting emotional intelligence (Trait Meta-Mood scale [TMM]; Interpersonal Reactivity Index [IRI]), mindfulness, and gratitude. We conducted post hoc Tukey tests on statistically significant models. Resident physicians from both the IMR and control group were combined in these analyses, therefore no baseline differences were controlled for in the analyses. We performed Pearson's correlations at baseline to examine the interrelationship between burnout, well-being and protective factor measures (see Supplemental Table at https:// journals.stfm.org/media/3462/supplement-table1-ricker.pdf).

\section{Results}

\section{Baseline Group Differences}

We conducted analyses comparing the baseline status of the IMR and control group (CG) resident physicians. There were no demographic differences between the two groups. However, we found a statistically significant difference between the groups for MBI emotional exhaustion (IMR mean: 15.6 vs CG mean $21.23 ; P=.005)$ and MBI depersonalization (IMR mean: 5.8 vs CG Mean 8.6; $P=.007)$. In both cases, the IMR group had lower scores than the control group. No other statistically significant differences were found on the assessments at the start of residency. 
Table 1: Study Measures

\begin{tabular}{|c|c|c|c|}
\hline Dimension & Measure & Description & Interpretation \\
\hline Burnout & $\begin{array}{l}\text { Maslach Burnout } \\
\text { Inventory (MBI) }\end{array}$ & $\begin{array}{l}22 \text { items; } 3 \text { subscales: } \\
\text { - Emotional exhaustion (EE) - feelings of } \\
\text { being emotionally overextended and } \\
\text { exhausted by one's work; } \\
\text { - Depersonalization (DEP) - an unfeeling } \\
\text { and impersonal response toward } \\
\text { recipients of one's care; } \\
\text { - Personal accomplishment (PA) - } \\
\text { feelings of competence and successful } \\
\text { achievement in one's work with } \\
\text { people. } \\
\text { Burnout risk level groups were created } \\
\text { based on normative data for medical } \\
\text { providers as described in the MBI } \\
\text { manual. }\end{array}$ & $\begin{array}{l}\text { Higher scores indicate greater EE, DEP } \\
\text { and PA. } \\
\text { Risk level group: } \\
\text { - High risk - scoring in the high } \\
\text { burnout category on EE and DEP; } \\
\text { - Low risk - scoring in the low burnout } \\
\text { category on EE and DEP; } \\
\text { - Moderate risk - remaining } \\
\text { individuals. }\end{array}$ \\
\hline Well-being & $\begin{array}{l}\text { Perceived Stress } \\
\text { Scale (PSS) }{ }^{33,34}\end{array}$ & $\begin{array}{l}10 \text { items; } \\
\text { Tap how unpredictable, uncontrollable, } \\
\text { and overloaded respondents find their } \\
\text { lives to be within the past month. }\end{array}$ & Higher scores indicate more stress. \\
\hline Well-being & $\begin{array}{l}\text { Center for } \\
\text { Epidemiologic } \\
\text { Studies - } \\
\text { Depression Scale } \\
(\text { CES-D) })^{35}\end{array}$ & $\begin{array}{l}20 \text { items; screening test for depression } \\
\text { and depressive disorder, measuring } \\
\text { symptoms defined by the American } \\
\text { Psychiatric Association' Diagnostic and } \\
\text { Statistical Manual for a major depressive } \\
\text { episode. }\end{array}$ & $\begin{array}{l}\text { Higher scores indicate greater risk for } \\
\text { clinical depression. }\end{array}$ \\
\hline Well-being & $\begin{array}{l}\text { Satisfaction with } \\
\text { Life Scale }{ }^{36,37}\end{array}$ & 5 -item global measure of life satisfaction. & $\begin{array}{l}\text { Higher scores indicate greater life } \\
\text { satisfaction. }\end{array}$ \\
\hline Well-being & $\begin{array}{l}\text { Positive and } \\
\text { Negative Affect } \\
\text { Scale }^{38}\end{array}$ & $\begin{array}{l}20 \text { items; } 2 \text { subscales: } \\
\text { - Positive affect; } \\
\text { - Negative affect }\end{array}$ & $\begin{array}{l}\text { Higher score indicates more positive, } \\
\text { more negative affect }\end{array}$ \\
\hline $\begin{array}{l}\text { Protective } \\
\text { factor }\end{array}$ & $\begin{array}{l}\text { Interpersonal } \\
\text { Reactivity Index } \\
39,40\end{array}$ & $\begin{array}{l}21 \text { items; } 3 \text { subscales that measure } \\
\text { emotional intelligence: } \\
\text { - Perspective taking; } \\
\text { - Empathic concern; } \\
\text { - Personal distress }\end{array}$ & $\begin{array}{l}\text { Higher scores indicate greater } \\
\text { perspective taking, greater empathic } \\
\text { concern, greater personal distress }\end{array}$ \\
\hline $\begin{array}{l}\text { Protective } \\
\text { factor }\end{array}$ & Trait Meta-Mood ${ }^{41}$ & $\begin{array}{l}30 \text { items } 3 \text { subscales that measure } \\
\text { emotional intelligence: } \\
\text { - Attention to feelings: how much } \\
\text { attention one pays to inner feelings; } \\
\text { - Clarity of experience of feelings: ability } \\
\text { to understand and discriminate } \\
\text { among feelings; } \\
\text { - Repair of emotions: ability to regulate } \\
\text { moods and repair negative emotions. }\end{array}$ & $\begin{array}{l}\text { Higher scores indicate greater attention } \\
\text { to feelings, clarity, and emotion repair }\end{array}$ \\
\hline $\begin{array}{l}\text { Protective } \\
\text { factor }\end{array}$ & Gratitude $^{42}$ & $\begin{array}{l}\text { 6-item scale designed to assess individual } \\
\text { differences in the proneness to experience } \\
\text { gratitude in daily life. }\end{array}$ & Higher scores indicate more gratitude. \\
\hline $\begin{array}{l}\text { Protective } \\
\text { factor }\end{array}$ & $\begin{array}{l}\text { Freiberg } \\
\text { Mindfulness } \\
\text { Inventory }^{43}\end{array}$ & $\begin{array}{l}14 \text { items measuring mindfulness in a } \\
\text { generalized context. }\end{array}$ & Higher score indicates more mindfulness \\
\hline
\end{tabular}


Longitudinal Analyses

We observed significant correlations between most of the measures (see Supplemental Table), with MBI personal accomplishment, gratitude, emotional intelligence/TMM total and repair of emotions and clarity of feelings subscales significantly correlated with all of the other measures, while IRI (empathic concern) and TMM (attention to feelings) showed the least significant intercorrelations. Although the measures tended to be intercorrelated, the magnitudes of the correlations between the measures show that they are not redundant indicators for exactly the same underlying constructs. Therefore, we conducted separate models for each of the measures.

The group by time interaction and group main effect were nonsignificant in each of the models indicating no differences between the IMR and control group. The effect of time was statistically significant in all models $(P<.01)$ with the exception of depression $(P=.17)$, mindfulness $(P=.75)$, gratitude $(P=.06)$, and TMM clarity of experience of feeling $(P=.26)$. In examining the statistically significant change over time results, two distinct patterns of change in wellbeing emerged. In the case of the two burnout scales, emotional exhaustion and depersonalization increased between the start of residency and remained elevated at graduation. In the second pattern, while a decrement between residency start and PGY2 was not always present; we found improvements in well-being between PGY2 and graduation. We observed this pattern for perceived stress, Positive and Negative Affect Scale (PANAS) positive and negative affect, satisfaction with life, and MBI personal accomplishment. In addition, satisfaction with life and negative affect were significantly improved over residency start. Only PANAS positive affect and MBI personal accomplishment showed the decline between residency start and PGY2. However, unlike emotional exhaustion and depersonalization, these measures returned to baseline levels at graduation (Figure 1).

The overall pattern observed for emotional intelligence indicated a decline during residency (Figure 2). Similar to the pattern observed for the two MBI burnout scales, TMM repair of emotions, TMM total score, and IRI empathic concern decreased between residency start and PGY2 and remained decreased at graduation. While not showing the initial decrease at PGY2, TMM attention

Figure 1: Changes in Burnout and Well-being

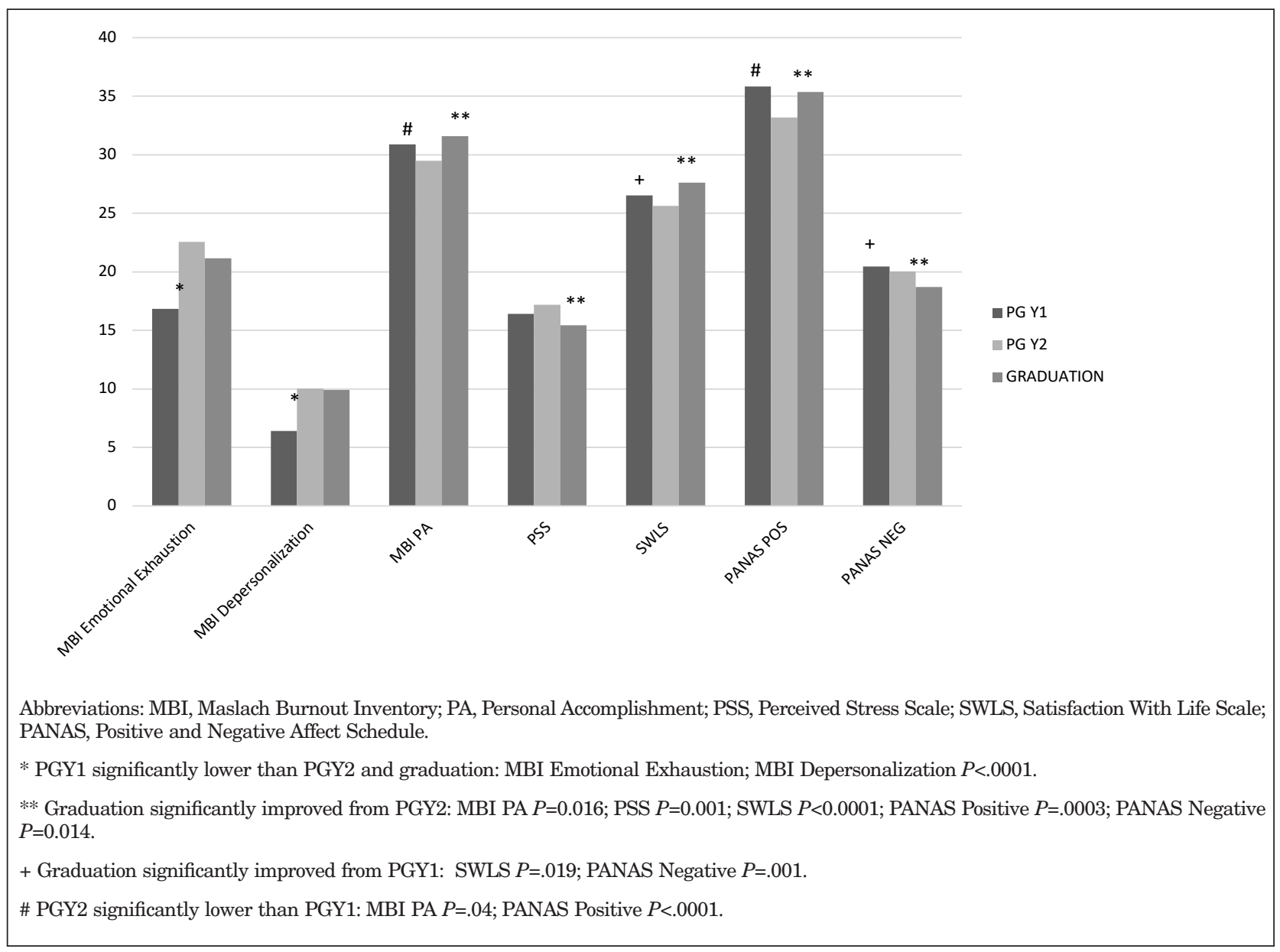


Figure 2: Changes in Emotional Intelligence

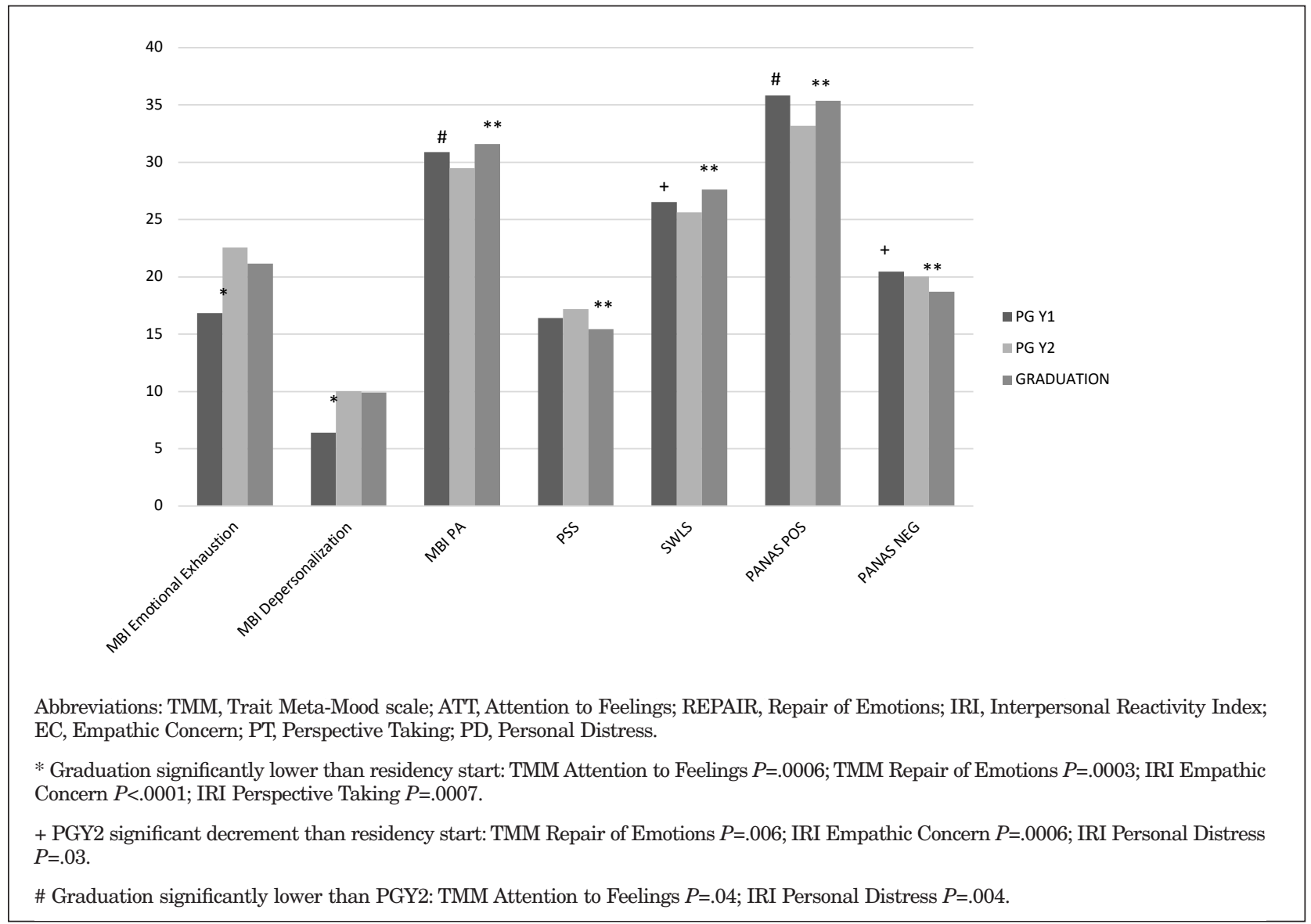

to feelings and IRI perspective taking were lower at graduation than start of residency. TMM attention to feelings was also lower at graduation than PGY2. Unlike the other emotional intelligence variables, IRI personal distress increased between residency start and PGY2; however, it returned to residency start levels at graduation.

\section{Impact of Burnout Risk Group}

Burnout risk group was available for 152 resident physicians at graduation. Half of the resident physicians $(52 \%, \mathrm{n}=79)$ scored in the moderate risk group, while $25 \%(\mathrm{n}=38)$ scored in the high-risk burnout group. Less than one-fourth ( $23 \%, \mathrm{n}=35$ ) scored as low risk. In the models examining the impact of burnout risk group, statistically significant models were found for TMM subscales, repair of emotions and clarity of experience of feeling, overall TMM score, IRI empathic concern, mindfulness, and gratitude. In the post hoc comparisons, the high-risk group was significantly lower than both the low and moderate risk groups on TMM repair of emotions, TMM clarity of experience of feeling, TMM total score, and gratitude. In the mindfulness and IRI empathic concern models, the high-risk group was significantly lower than the low-risk group only (Table 2).

\section{Discussion}

This is the first large multisite study to explore resident physician wellbeing over the course of residency using a variety of standardized psychological measures that evaluate not just burnout, but multidimensional aspects of well-being and protective factors. The findings indicate that while the stressful impact of residency is transitory for some measures of well-being, that is not the case for burnout or emotional intelligence. Burnout levels peak after the first year of residency and remain high throughout residency until graduation. Not only did emotional intelligence decline during residency, it was lower at graduation than at residency start. The relationship between burnout and emotional intelligence, mindfulness, and gratitude was evident at graduation. Lower scores were observed on these protective factor measures in the high burnout group than in the low burnout group, and in some cases, scores were worse than the moderate burnout group as well. This has implications for the graduating physician, potentially starting their careers with minimal protective factors in the context of ample burnout.

In contrast to the burnout and emotional intelligence findings, measures of well-being improved between PGY2 and graduation, 
Table 2: Impact of Burnout Risk Level on Emotional Intelligence, Mindfulness, and Gratitude-Means and Standard Deviations

\begin{tabular}{|l|c|c|c|c|c|c|c|c|}
\hline \multirow{2}{*}{\multicolumn{1}{|c|}{ Variable }} & \multicolumn{2}{c|}{ Low Risk } & \multicolumn{2}{c|}{ Moderate Risk } & \multicolumn{2}{c|}{ High Risk } & \multirow{2}{*}{ Test Statistic } & \multirow{2}{*}{$\boldsymbol{P}$ Value } \\
\cline { 2 - 8 } & Mean & SD & Mean & SD & Mean & SD & & \\
\hline TMM Attention to Feeling & 50.47 & 50.47 & 50.34 & 50.34 & 47.42 & 47.42 & $F(2,145)=1.76$ & .176 \\
\hline TMM Clarity Experience Feeling* & 43.35 & 5.81 & 41.89 & 6.16 & 38.63 & 8.42 & $F(2,145)=4.84$ & .009 \\
\hline TMM Repair of Emotions* $^{*}$ & 24.41 & 3.82 & 24.00 & 3.49 & 21.13 & 5.43 & $F(2,145)=7.50$ & .001 \\
\hline TMM Total Score* $^{*}$ & 118.24 & 13.26 & 116.24 & 13.66 & 107.18 & 20.67 & $F(2,145)=5.57$ & .005 \\
\hline IRI Empathic Concern $^{+}$ & 22.21 & 4.53 & 21.05 & 4.31 & 19.21 & 5.13 & $F(2,146)=4.00$ & .020 \\
\hline IRI Personal Distress $^{*}$ & 7.09 & 4.85 & 8.65 & 4.46 & 9.39 & 4.51 & $F(2,146)=2.40$ & .095 \\
\hline IRI Perspective Taking $^{*}$ & 19.91 & 5.15 & 19.23 & 4.72 & 17.45 & 4.95 & $F(2,146)=2.60$ & .078 \\
\hline Mindfulness $^{+}$ & 41.49 & 7.17 & 37.91 & 8.37 & 35.59 & 5.76 & $F(2,147)=5.61$ & .005 \\
\hline Gratitude* $^{*}$ & 39.88 & 3.74 & 38.41 & 4.40 & 34.30 & 6.60 & $F(2,141)=12.78$ & $<.001$ \\
\hline
\end{tabular}

Abbreviations: TMM, Trait Meta-Mood; IRI, Interpersonal Reactivity Index.

*High risk $<$ low, moderate risk $P<.05$.

${ }^{+}$High risk $<$low risk $P<.02$.

satisfaction with life was higher and negative affect was lower at graduation than at residency start. Greater satisfaction with life at the end of residency compared to the start was also found in a cross-sectional study with emergency medicine resident physicians. ${ }^{45}$ One explanation for the improvement in this well-being indicator is that resident physicians at the end of their training are more confident in their professional skills and find pride in their work and abilities, as evidenced by the increase in personal accomplishment at graduation. Also, fewer call duties, after hours, and weekend workload toward the end of residency resulting in more free time could increase residents' satisfaction with life as they can spend more time with loved ones, being physically active, outdoors, etc. However, the increase in burnout and decrease in emotional intelligence may be explained by cumulative discontent with work-related issues such as decrease in time available to see patients, increase in administrative work, increase in patient visits expectations, and increase in time using the electronic health record. ${ }^{46}$

An important limitation of this study is the age of the data set: resident physicians graduated in
2011-2013. Since that time, new strategies to impact residency wellbeing may have occurred at any of the program sites utilized for this study. Additionally, the implementation of the new ACGME requirements on July 1, 2017 may have resulted in more intentional wellness programs during residency training in general. However, the rates of burnout have remained high. ${ }^{13}$ Similar to the pattern observed in our study, a longitudinal study of surgical resident physicians (surveyed in 2016) found a similar increase in burnout over the intern year. ${ }^{26}$ In a cross-sectional study of surgical resident physicians based on the same survey data set, the percentage of resident physicians with emotional exhaustion was greatest for PGY2 and lowest for a nonclinical year. ${ }^{5}$

Despite the age of our data, the results are still relevant. The observed relationship between burnout and the protective factors emphasizes the importance of identifying and addressing burnout in residency as it may affect the most formative years for a family physician and the ability to establish healing relationships with their patients. As new studies research burnout prevention and resident well-being programs and policies, there needs to be ongoing evaluation to determine best practices in burnout prevention and mitigation and ongoing monitoring of resident physician burnout. Family medicine residency graduates entering practice need to be resilient and prepared to meet the demands of primary care practice.

ACKNOWLEDGMENTS: The authors thank Janice Curtis and Mei-Kuang Chen, PhD, for their invaluable assistance in preparing this manuscript.

FINANCIAL SUPPORT: Funding for the Integrative Medicine in Residency program and its evaluation has been provided by a congressionally-directed grant administered through the US Department of Education. Contents do not necessarily represent the policy of the Department of Education and do not assume endorsement by the Federal Government. Additional support comes from the Weil Foundation, the David C. and Lura M. Lovell Foundation, the Joan B. Diamond Charitable Lead Trust, and multiple generous individuals.

PRESENTATIONS: This study was partially reported at the 2014 Society of Teachers of Family Medicine Annual Spring Conference in San Antonio, Texas; the 2014 International Research Congress on Integrative Medicine \& Health, in Miami, Florida; and the 2014 North American Primary Care Research Group 42nd Annual Meeting in New York City.

CORRESPONDING AUTHOR: Address correspondence Dr Patricia Lebensohn, Andrew Weil Center for Integrative Medicine, PO Box 245153, Tucson, AZ 85724-5153. 520-975-8138. Fax: 520-626-6484. plebenso@email.arizona. edu. 


\section{References}

1. Accreditation Council for Graduate Medical Education. Common Program Requirements Section VI With Background and Intent. 2017. https://www.acgme.org/Portals/0/PFAssets/ProgramRequirements/CPRs_Section\%20VI_withBackground-and-Intent_2017-01.pdf. Accessed January 16, 2019. pp. 8,10.

2. Lebensohn P, Dodds S, Benn R, et al. Resident wellness behaviors: relationship to stress, depression, and burnout. Fam Med. 2013;45(8):541-549.

3. Reed S, Kemper KJ, Schwartz A, et al. Variability of burnout and stress measures in pediatric residents: an exploratory single-center study from the pediatric resident burnout-resilience study consortium. J Evid Based Integr Med. 2018;23:2515690X18804779.

4. Shanafelt TD, Balch CM, Dyrbye L, et al. Special report: suicidal ideation among American surgeons. Arch Surg. 2011;146(1):54-62.

5. Lebares CC, Guvva EV, Ascher NL, O'Sullivan PS, Harris HW, Epel ES. Burnout and stress among US surgery residents: psychological distress and resilience. J Am Coll Surg. 2018;226(1):80-90

6. de Oliveira GS Jr, Chang R, Fitzgerald PC, et al. The prevalence of burnout and depression and their association with adherence to safety and practice standards: a survey of United States anesthesiology trainees. Anesth Analg. 2013;117(1):182-193

7. Tawfik DS, Profit J, Morgenthaler TI, et al. Physician burnout, well-being, and work unit safety grades in relationship to reported medical errors. Mayo Clin Proc. 2018;93(11):15711580.

8. Bodenheimer T, Sinsky C. From triple to quadruple aim: care of the patient requires care of the provider. Ann Fam Med. 2014;12(6):573576 .

9. Schaufeli Wilmar B, Leiter Michael P, Maslach C. Burnout: 35 years of research and practice. Career Dev Int. 2009;14(3):204-220.

10. Bianchi R, Schonfeld IS, Laurent E. Burnoutdepression overlap: a review. Clin Psychol Rev. 2015;36:28-41.

11. Dyrbye L, Shanafelt T. A narrative review on burnout experienced by medical students and residents. [Review]. 2016;1(1):132-149.

12. Lindeman B, Petrusa E, McKinley S, et al. Association of Burnout With Emotional Intelligence and Personality in Surgical Residents: Can We Predict Who Is Most at Risk? J Surg Educ. 2017;74(6):e22-e30.

13. Dyrbye LN, Burke SE, Hardeman RR, et al. Association of Clinical Specialty With Symptoms of Burnout and Career Choice Regret Among US Resident Physicians. JAMA. 2018;320(11):1114-1130.

14. McKinley TF, Boland KA, Mahan JD. Burnout and interventions in pediatric residency: $\mathrm{A}$ literature review. Burn Res. 2017;6:9-17.

15. Shanafelt TD, West CP, Sinsky C, et al. Changes in burnout and satisfaction with work-life integration in physicians and the general US working population between 2011 and 2017 . Mayo Clin Proc. 2019;94(9):1681-1694.

16. Raj KS. Well-being in residency: a systematic review. J Grad Med Educ. 2016;8(5):674-684.
17. Reuben DB. Depressive symptoms in medical house officers. Effects of level of training and work rotation. Arch Intern Med. 1985;145(2):286-288.

18. Sen S, Kranzler HR, Krystal JH, et al. A prospective cohort study investigating factors associated with depression during medical internship. Arch Gen Psychiatry. 2010;67(6):557565.

19. Mata DA, Ramos MA, Bansal N, et al. Prevalence of depression and depressive symptoms among resident physicians: a systematic review and meta-analysis. JAMA. 2015;314(22):2373 2383.

20. Campbell J, Prochazka AV, Yamashita T, Gopa R. Predictors of persistent burnout in internal medicine residents: a prospective cohort study Acad Med. 2010;85(10):1630-1634.

21. Fahrenkopf AM, Sectish TC, Barger LK, et al. Rates of medication errors among depressed and burnt out residents: prospective cohort study. BMJ. 2008;336(7642):488-491.

22. Scheier MF, Carver CS. Effects of optimism on psychological and physical well-being: theoretical overview and empirical update. Cognit Ther Res. 1992;16(2):201-228.

23. Dodge R, Daly AP, Huyton J, Sanders LD. The challenge of defining wellbeing. Int J Wellbeing. 2012;2(3):222-235.

24. Salovey P, Mayer JD. Emotional intelligence. Imagination, cognition and personality. 1990;9(3):185-211.

25. Nedrow A, Steckler NA, Hardman J. Physician resilience and burnout: can you make the switch? Fam Pract Manag. 2013;20(1):25-30.

26. Lebares CC, Braun HJ, Guvva EV, Epel ES, Hecht FM. Burnout and gender in surgical training: A call to re-evaluate coping and dysfunction. Am J Surg. 2018;216(4):800-804

27. Williams D, Tricomi G, Gupta J, Janise A. Efficacy of burnout interventions in the medical education pipeline. Acad Psychiatry. 2015;39(1):47-54.

28. Lebensohn P, Kligler B, Brooks AJ, et al. Integrative medicine in residency: feasibility and effectiveness of an online program. Fam Med. 2017;49(7):514-521.

29. Lebensohn P, Kligler B, Dodds S, et al. Integrative medicine in residency education: developing competency through online curriculum training. J Grad Med Educ. 2012;4(1):76-82.

30. Accreditation Council for Graduate Medical Education. Public. https://apps.acgme.org/ads/ Public. Accessed February 20, 2020.

31. Maslach C. Maslach Burnout Inventory. From: https://www.mindgarden.com/117-maslachburnout-inventory-mbi. Accessed August 27 2020

32. Maslach CJ. SE, Leiter, MP. Maslach Burnout Inventory. 3rd ed. Palo Alto, CA: Consulting Psychologists Press; 1996.

33. Cohen S W, G. Perceived stress in a probability sample of the United States. In: Spacapan S ed. The social psychology of health: Claremont symposium on applied social psychology. Newbury Park, CA: Sage; 1988.

34. Lee EH. Review of the psychometric evidence of the perceived stress scale. Asian Nurs 2012;6(4):121-127.
35. Radloff LS. The CES-D Scale: A self-report depression scale for research in the general population. Appl Psychol Meas. 1977;1(3):385401.

36. Diener E, Emmons RA, Larsen RJ, Griffin S. The satisfaction with life scale. J Pers Assess. 1985;49(1):71-75.

37. Pavot W, Diener E. Review of the satisfaction with life scale. Psychol Assess. 1993;5(2):164172 .

38. Watson D, Clark LA, Tellegen A. Development and validation of brief measures of positive and negative affect: the PANAS scales. J Pers Soc Psychol. 1988;54(6):1063-1070. 3

39. Davis MH. A multidimensional approach to individual differences in empathy. Catal Sel Doc Psychol. 1980.

40. Davis MH. Measuring individual differences in empathy: evidence for a multidimensional approach. J Pers Soc Psychol. 1983;44(1):113126.

41. Salovey P, Mayer JD, Goldman SL, Turvey C, Palfai TP. Emotional attention, clarity, and repair: exploring emotional intelligence using the Trait Meta-Mood Scale. In: Emotion, disclosure, \& health. Washington, DC: American Psychological Association; 1995:125-154.

42. Mccullough ME, Emmons RA, Tsang JA. The grateful disposition: a conceptual and empirical topography. J Pers Soc Psychol. 2002;82(1):112127.

43. Walach H, Buchheld N, Buttenmüller V, Kleinknecht N, Schmidt S. Measuring mindfulness - the Freiburg Mindfulness Inventory (FMI). Pers Individ Dif. 2006;40(8):1543-1555.

44. Galwey N. The Use of Mixed Models for the Analysis of Unbalanced Experimental Designs. Introduction to Mixed Modelling. Chichester, UK: John Wiley \& Sons, Ltd; 2014:350-378.

45. Hoonpongsimanont W, Murphy M, Kim CH, Nasir D, Compton S. Emergency medicine resident well-being: stress and satisfaction. Occup Med (Lond). 2014;64(1):45-48.

46. Gardner RL, Cooper E, Haskell J, et al. Physician stress and burnout: the impact of health information technology. J Am Med Inform Assoc. 2019;26(2):106-114. 